\title{
DIFFERENCES IN EFFECTS OF SPIRONOLACTONE AND PHENOBARBITAL ON THE HEPATIC-THYROID AXIS IN MALE RATS
}

\author{
Jiro Sugimoto, Shigeru Tamura, Mutsumi Tamura, Yoshimi Inoue, and \\ Masumi Tanigami \\ Toxicology Laboratory, Research Center, Mitsubishi Kasei Corporation. Research Center
}

\begin{abstract}
Treatment with $150 \mathrm{mg} / \mathrm{kg}$ of spironolactone (SPL) and $100 \mathrm{mg} / \mathrm{kg}$ of phenobarbital (PB) for 13 weeks increased thyroid weight, numbers of apical vesicles and colloid droplets in thyroid follicular cells, and thyroid follicular hypertrophy. The patterns of elevated serum thyrotropin (TSH) and transiently decreased serum thyroxine $\left(T_{4}\right)$ and triiodothyronine $\left(T_{3}\right)$ suggest that thyroid follicular hypertrophy is a compensatory reaction to lowered thyroid hormone levels. Treatment with PB or SPL induced increased liver weight, hepatocellular hypertrophy, and smooth endoplasmic reticulum proliferation in hepatocytes. PB-treatment increased Uridine diphosphate glucuronosyl transferase (UDP-GT) activity toward $p$-nitrophenol and P-450 content but SPL-treatment had no such effect on hepatic microsomal enzymes. PB and SPL have been shown not to directly affect thyroid hormone synthesis. It is concluded that the effect of PB on thyroid function in male rats is secondary to increased hepatic UDPGT and P-450 and that in SPL-treated male rats a distinct spectrum of isozymes of cytochrome P-450 and UDP-GT and/or other enzymes may play an important role for induction of thyroid hypertrophy. (J Toxicol Pathol $7: 211 \sim 222,1994$ )

Key words: Spironolactone, Phenobarbital, Thyroid, Liver, Uridine diphosphate glucuronosyl trans ferase
\end{abstract}

\section{Introduction}

Hepatic microsomal enzymes alter both the metabolism of xenobiotic substances and that of various endogenous substances such as steroids and endocrine hormones including cortisol ${ }^{1}$, testosterone $e^{2}$, estrogens ${ }^{3}$, and thyroxine ${ }^{4,5}$. Hormones cannot be regulated by synthesis and secretion alone; they must also be metabolized and eliminated. Thus, the hepatic-endocrine axis plays an important role in hormone homeostasis.

Phenobarbital (PB) has been extensively studied as a prototype for a class of microsomal enzyme inducers that induce a similar spectrum of cytochrome $\mathrm{P}-450$ isozymes ${ }^{6}$. The goitrogenic effect of $P B$ in rats is characterized by increased

杉本次郎 田村 茂 田村 睦 井上芳巳 谷上真寿美 Accepted for publication: April 7, 1994

Mailing address : Jiro Sugimoto, Toxicology Laboratory, Research Center, Mitsubishi Kasei Corporation, Research Center, 1000, Kamoshida-cho, Midori-Ku, Yokohama 227. thyroid gland weight and hypertrophy and hyperplasia of thyroid follicular cells ${ }^{7}$. Goldstein and Taurog concluded that the increased biliary excretion of thyroxine $\left(T_{4}\right)$ as caused such thyroid gland change in PB-treated rats ${ }^{8}$. Such changes in thyroid and liver are likely due to activated thyrotropin (TSH) response that occured in compensation for decreased serum $T_{4}$ concentration caused by an increase in its metabolic clearance $^{9-11}$.

Spironolactone (SPL), an aldosterone antagonist, is effective against primary aldostenonism ${ }^{12,13}$, low ascites, renin essential hypertension ${ }^{14-16}$, and disorders of spontaneous or iatrogenic hypokalemia ${ }^{17,18}$. Thyroid follicular hypertrophy and hyperplasia and a dose-related increase in liver weight have been described in 78- and 104week study on the effects of SPL in rats ${ }^{19}$. By increasing hepatic clearance of $T_{4}, S P L$ caused a decrease in the serum concentration of this hormone and followed by a release of feed back 
inhibition and an increase in TSH resulting in the increased in thyroid gland size and activity ${ }^{20}$. Thus, the effects of thyroid and liver in SPL-treated rats resemble those in PB-treated rats. Longterm administration of $\mathrm{PB}$ in rats has induced no thyroid follicular tumors without the initiation by nitrosamine or nitrosourea ${ }^{21}$. On the other hand, long-term administration of SPL in rats has induced the thyroid follicular lasions categorized as "adenomas". We have been interested in the difficult results of two long-term administration tests. The objectives of this investigations were to characterize and determine the relationship between thyroid and hepatic effects of SPL compared with that of $\mathrm{PB}$ and to discover the difference in these two drugs.

\section{Materials and Methods}

\section{Chemicals}

Spironolactone was obtained from Wako Pure Chem. Co. (Osaka, Japan). Phenobarbital was purchased from Mitubishikasei Co. (Tokyo, Japan).

\section{Animals and treatment}

Male Sprague-Dawley-derived CD rats (6 weeks of age), obtained from Charles River Laboratories (Kanagawa, Japan) were assigned to three groups of 18 animals each by random selection and were orally administrated with $100 \mathrm{mg} / \mathrm{kg} /$ day of PB, $150 \mathrm{mg} / \mathrm{kg} /$ day of SPL or $0.5 \%$ (w/v) carboxymethylcellulose sodium, used as vehecle. Six animals from each group were sacrificed after 3 days, 3 weeks, and 13 weeks of the treatment (Table 1). Two animals each were housed in a polycarbonate cage with hardwood chip bedding under an air-conditioned environment at $20-24^{\circ} \mathrm{C}$, 40-70\% humidity and a $12 \mathrm{~h}$ light/dark cycle. All the animals were given rodent chow (MF, Oriental Yeast Co., Ltd., Tokyo, Japan) and tap water ad libitum. At the end of dosing, the animals were anesthetized by intraperitoneal administration of pentobarbital and were exsanguinated via the abdominal vein after blood collection was sampled. The serum samples were stored at $-80^{\circ} \mathrm{C}$. TSH, triiodothyronine $\left(T_{3}\right)$ and $T_{4}$ were determined by radioimmunoassay. Anti-TSH antibody was rat-specific and assayed by Dr. Wa-

Table 1. Experimental Design

\begin{tabular}{lccccc}
\hline Group & \multirow{2}{*}{$\begin{array}{c}\text { Dose } \\
(\mathrm{mg} / \mathrm{kg})\end{array}$} & Number $^{\mathrm{a}}$ & & \multicolumn{3}{c}{ Sacrifice schedule $^{\mathrm{b}}$} & 3 day & 3 week & 13 week \\
\hline Control & 0 & 18 & 6 & 6 & 6 \\
SPL & 150 & 18 & 6 & 6 & 6 \\
PB & 100 & 18 & 6 & 6 & 6 \\
\hline
\end{tabular}

a Number of rats/group.

- Days or weeks are times following start of the test.

Values are number of rats killed.

SPL, spironolactone; PB, phenobarbital.

Table 2. Thyroid Weight and Thyroid-to-body Weight Ratios ${ }^{a}$

\begin{tabular}{|c|c|c|c|c|c|c|}
\hline \multirow{2}{*}{ Group } & \multicolumn{3}{|c|}{$\begin{array}{l}\text { thyroid weight } \\
\text { (mg) }\end{array}$} & \multicolumn{3}{|c|}{$\begin{array}{l}\text { thyroid/body weight } \\
\text { ratio }\left(\times 10^{-3}\right)\end{array}$} \\
\hline & 3 day & 3 week & 13 week & 3 day & 3 week & 13 week \\
\hline Control & $12.9 \pm 1.48$ & $18.7 \pm 2.23$ & $23.3 \pm 4.44$ & $6.8 \pm 0.93$ & $5.5 \pm 0.95$ & $4.0 \pm 0.67$ \\
\hline SPL & $14.9 \pm 3.49$ & $25.2 \pm 4.13^{* *}$ & $27.7 \pm 2.18$ & $8.3 \pm 2.15$ & $7.4 \pm 1.18^{*}$ & $4.9 \pm 0.49^{*}$ \\
\hline PB & $12.7 \pm 3.75$ & $22.1 \pm 4.87$ & $30.0 \pm 7.76^{b}$ & $6.7 \pm 1.84$ & $7.0 \pm 1.33^{*}$ & $6.0 \pm 0.97^{\circ *}$ \\
\hline
\end{tabular}

Data represent the mean \pm SD for 6 rats per group.

* Days or weeks are times following start of the test.

b Means with standard deviation of 3 animals.

${ }^{*}, \mathrm{p}<0.05 ;{ }^{* *}, \mathrm{p}<0.01$ for comparison with control values (Student's $t$-test)

SPL, spironolactone; PB, phenobarbital.

Fig. 1. Thyroids from control (A) and from rats receiving $150 \mathrm{mg} / \mathrm{kg}$ of SPL (B) and $100 \mathrm{mg} / \mathrm{kg}$ of PB (C) for 13 weeks. The colloids have diminished and are nonhomogeneous. Follicular epithelial cells in the rats receiving SPL or PB are taller and wider than in control rats and their cytoplasm is finely vacuolated. HE $\times 180$. 
Sugimoto, Tamura, Tamura, et al.
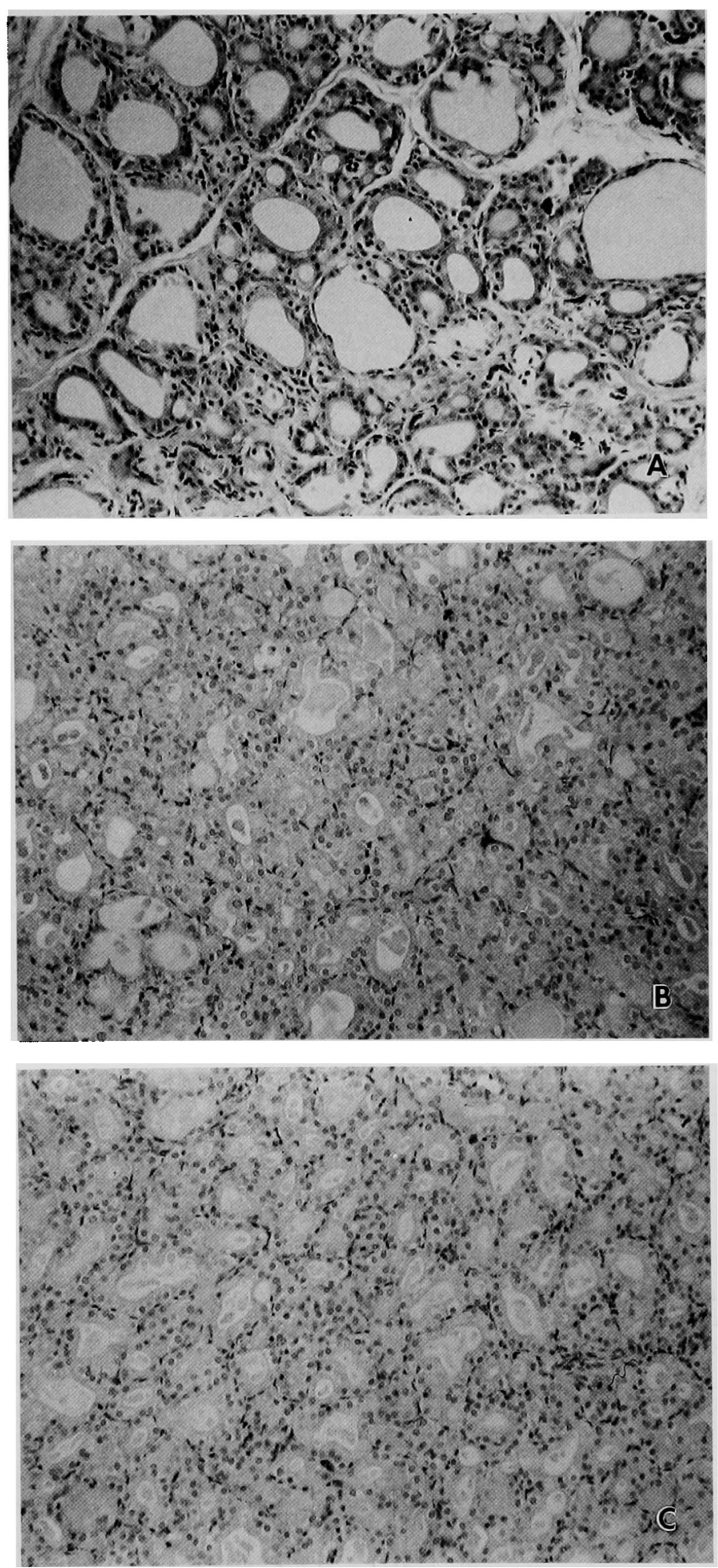
kabayashi of the University of Gumma of the Hormone Assay Center.

After the animals were sacrificed, the thyroids and livers were removed, weighed, and fixed in $10 \%$ buffered formalin. The tissues were embedded in paraffin, sectioned at $4 \mu \mathrm{m}$ thick and stained with hematoxylin and eosin (HE). For electron microscopy, thyroid and liver tissues were sampled from two animals per group at 13 weeks. Small blocks of these organs were fixed in $2.5 \%$ glutaraldehyde for 2 hours, postfixed in $2 \%$ osmium tetroxide for 2 hours, dehydrated in ethanol, passed through propylene oxide, and embedded in Quetol 812.

Ultrathin sections were made with LKB ultramicrotome, stained with uranyl acetate and lead nitrate, and examined with a Hitachi $\mathrm{H}-7000$ electron microscope (Hitachi, Ltd., Tokyo, Japan) at $75 \mathrm{kV}$.

\section{$P-450$ content and Uridine diphosphate glucur- onosyl transferase (UDP-GT) activity}

Microsomal fractions of liver samples from 5 control, 6 SPL-treated and 3 PB-treated animals sacrificed at week 13 were collected and measured for P-450 content and UDP-GT activity. P-450 content was determined by as described by Omura and $\mathrm{Sato}^{22}$. UDP-GT activity was determined based on the disappearance of p-nitrophenol using methods first described by Bock et $a l^{23}$.

\section{Statistical analysis}

Statistical significant differences in means with standard deviations against the non-treated group were assessed by the Student's $t$-test, with $\mathrm{p}<0.05$ as minimum significance.

\section{Results}

\section{Pathologic examination}

Thyroid: Thyroid weights and thyroid morphological lesions in SPL-treated animals resembled closely those in PB-treated animals. Increased thyroid weight was noted in SPL and PB groups at week 3 (Table 2). Thyroid-to-body weight ration significantly increased in the same groups at weeks 3 and 13 . These changes were slight at day 3 but quite prominent at weeks 3 and 13. In histologic examination, follicules in PB or SPL treated animals were smaller in size and lined by taller and wider epithelial cells with finely vacuolated cytoplasm when compared with the controls (Figs. 1A-1C). Some animals showed microfollicular hyperplasia featuring closely packed small follicules with little or no colloid

Table 3. Liver Weight and Liver-to-body Weight Ratios ${ }^{\mathrm{B}}$

\begin{tabular}{lcccccc}
\hline \multirow{2}{*}{ Group } & \multicolumn{3}{c}{ liver weight $(\mathrm{mg})$} & \multicolumn{3}{c}{ liver/body weight ratio $\left(\times 10^{-3}\right)$} \\
\cline { 2 - 7 } & \multicolumn{1}{c}{3 day } & 3 week & 13 week & 3 day & 3 week & 13 week \\
\hline Control & $8.35 \pm 0.58$ & $14.9 \pm 1.97$ & $20.2 \pm 3.94$ & $4.4 \pm 0.17$ & $4.3 \pm 0.31$ & $3.5 \pm 0.38$ \\
SPL & $9.37 \pm 0.86^{*}$ & $16.9 \pm 1.36^{* *}$ & $25.0 \pm 1.85^{*}$ & $5.2 \pm 0.47^{* *}$ & $5.0 \pm 0.24^{* *}$ & $4.4 \pm 0.29^{* *}$ \\
PB & $10.5 \pm 0.76^{* * *}$ & $18.1 \pm 2.44^{*}$ & $22.7 \pm 5.60^{\mathrm{b}}$ & $5.6 \pm 0.37^{* * *}$ & $5.5 \pm 0.22^{* * *}$ & $4.5 \pm 0.49^{\circ *}$ \\
\hline
\end{tabular}

Data represent the mean \pm SD for 6 rats per group.

a Days or weeks are times following start of the test.

b Means with standard deviation of 3 animals.

", $\mathrm{p}<0.05 ;{ }^{* *}, \mathrm{p}<0.01 ;{ }^{* * *}, \mathrm{p}<0.001$ for comparison with control values (Student's $t$-test)

SPL, spironolactone; PB, phenobarbital.

Fig. 2. Electron micrographs of thyroids from control and rats treated with $150 \mathrm{mg} / \mathrm{kg}$ of SPL and $100 \mathrm{mg} / \mathrm{kg}$ of $\mathrm{PB}$ for 13 weeks.

A. Control rat, $\times 10,500$.

B. Rat treated with SPL, $\times 10,500$. The follicular cells are enlarged with delayed rough endoplasmic reticulum and there are increased numbers of reabsorbed colloids. Apical vesicles are prominent.

C. Rat treated with $P B, \times 7,700$. The follicular cells are enlarged and dilated with rough endoplasmic reticulum and there are increased numbers of resorbed colloids and lysosomal bodies. Apical vesicles are prominent. 
Sugimoto, Tamura, Tamura, et al.
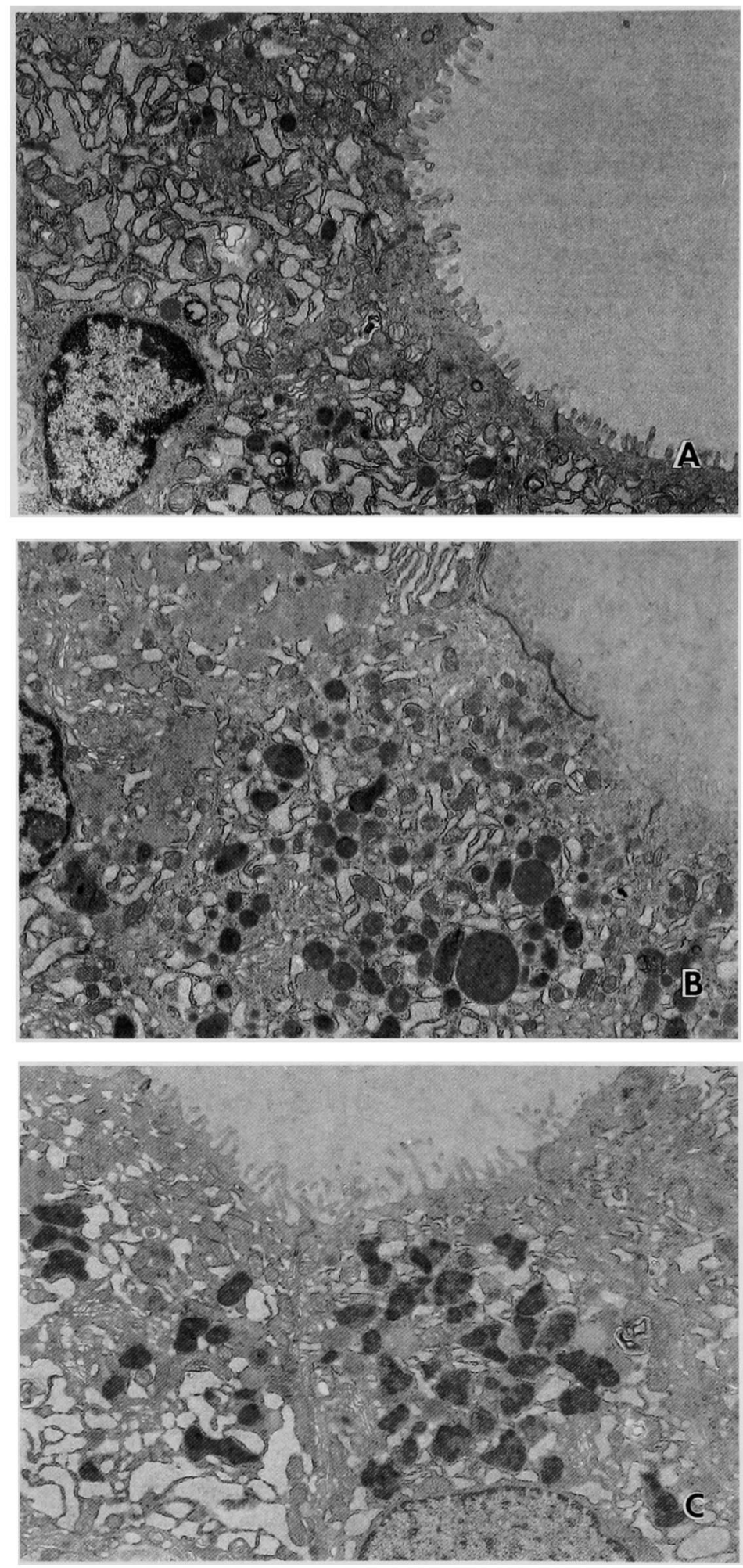

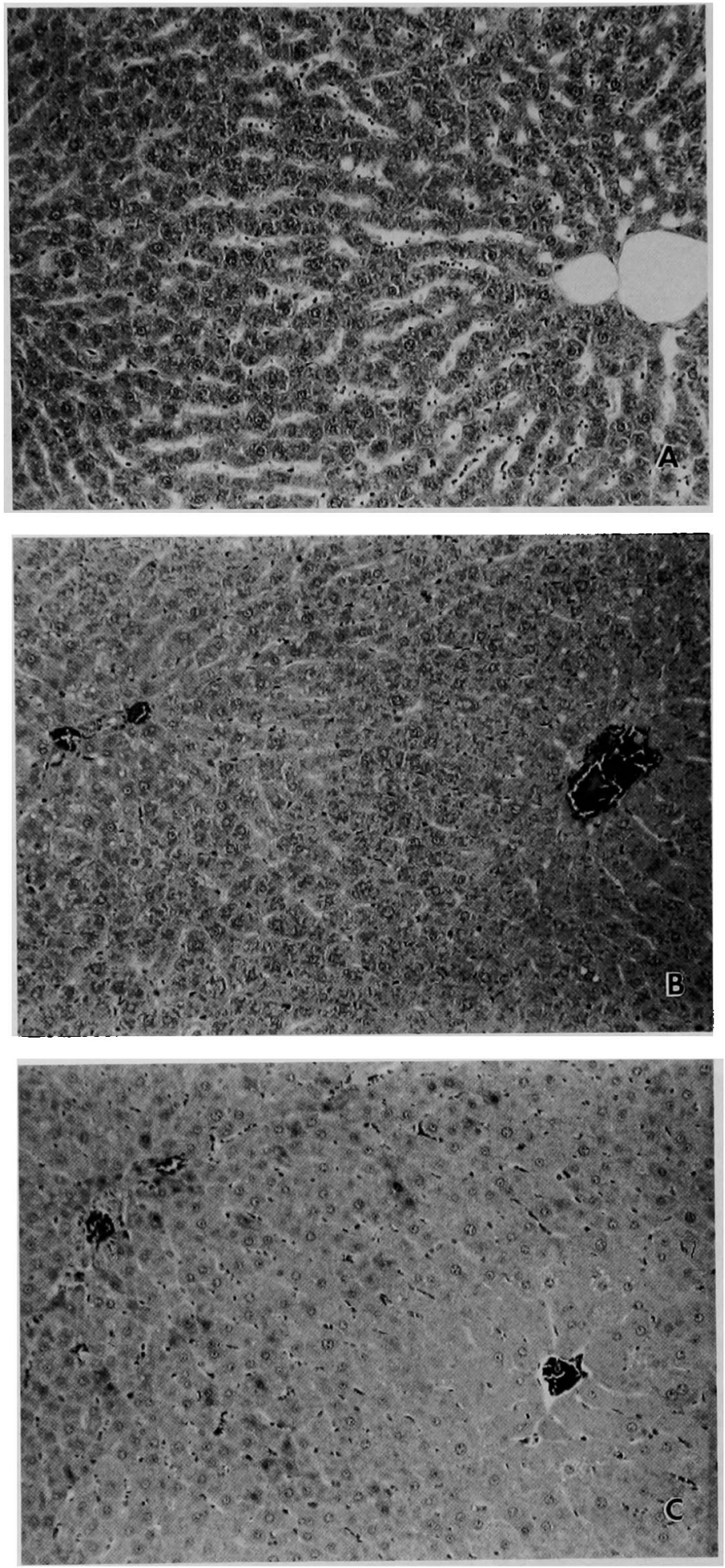


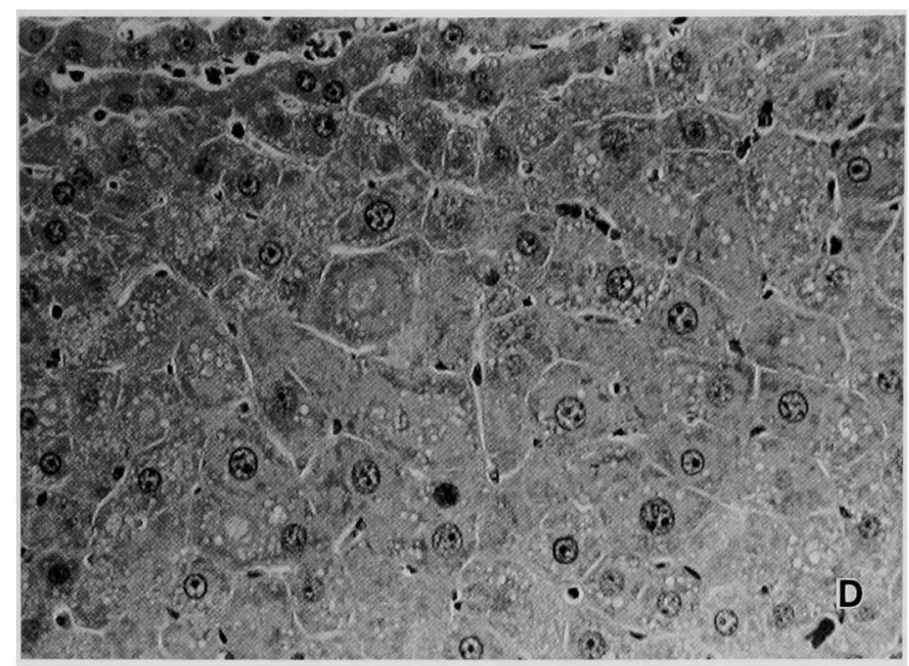

Fig. 3. Livers from control (A) and rats treated with $150 \mathrm{mg} / \mathrm{kg}$ of SPL (B) or $100 \mathrm{mg} / \mathrm{kg}$ of PB (C, D) for 13 weeks. HE

A. A control rat, $\times 180$.

B and C. Rats treated with SPL (B) or PB (C), $\times 180$.

Centrilobular hepatocytes are swollen and round.

D. A rat treated with PB, $\times 360$. Hepatocytes have intracellular eosinophilic inclusion bodies.

content. Electron microscopy revealed some changes in follicular cells in PB or SPL treated animals killed at 13 weeks (Figs. 2A-2C). The changes were characterized mainly by increased numbers of apical vesicles beneath the apical plasma membrane of follicular epithelial cells, representing secretion into the follicular lumen and increased numbers of colloid droplets located basally, representing reabsorbed intracellular colloid. Also, follicular cells showed dilated cisternae of rough endoplasmic reticulum and increased numbers of lysosomal bodies.

Liver : Animals given $150 \mathrm{mg} / \mathrm{kg}$ of SPL or $100 \mathrm{mg} / \mathrm{kg}$ of PB showed increased liver weight and liver-to-body weight ratio during the period of treatment (Table 3). Histologically, centrilobular hepatocellular hypertrophy was seen in animals from SPL and PB groups (Figs. 3A3D). This change was slight at day 3 but welldefined at weeks 3 and 13 . Intracellular eosinophilic inclusion bodies were seen in all animals from PB group at week 13 (Figs. 3D). No SPLtreated animals showed intracellular eosinophilic inclusion bodies. Electron microscopy demonstrated increased smooth endoplasmic reticulum in enlarged centrilobular hepatocytes in SPL or PB treated animals (Figs. 4A and 4B). Concentric membranous bodies of the endoplasmic reticulum were seen only in PB-treated animals (Figs. 4C). These membranous bodies appeared to correspond to intracellular eosinophilic inclusion bodies observed by light microscopy.

\section{Serum TSH, $T_{4}$, and $T_{3}$ concentrations}

Serum TSH concentrations significantly increased in SPL group at weeks 3 and 13 and in PB group at week 3 when compaired with control group (Fig. 5A). An upward trend of serum TSH concentrations was noted in PB group at week 13. Serum $T_{4}$ concentrations significantly decreased in PB group at 3 days and 3 weeks of treatment (Fig. 5B). Serum $T_{4}$ concentration was slightly lower in SPL group than in control group at 3 and 13 weeks. But there was no statistical difference between these two groups. The serum $T_{3}$ concentrations were significantly lower in PB group and in SPL group than in control at day 3 (Fig. 5C).

\section{Hepatic microsomal enzyme levels}

UDP-GT activity, as measured using $p$-nitrophenol as the substrate on the basis of one milligram of protein and one gram of liver significantly increased in the liver from animals treated with 100 $\mathrm{mg} / \mathrm{kg}$ of PB for 13 weeks (Table 4). Moreover, 

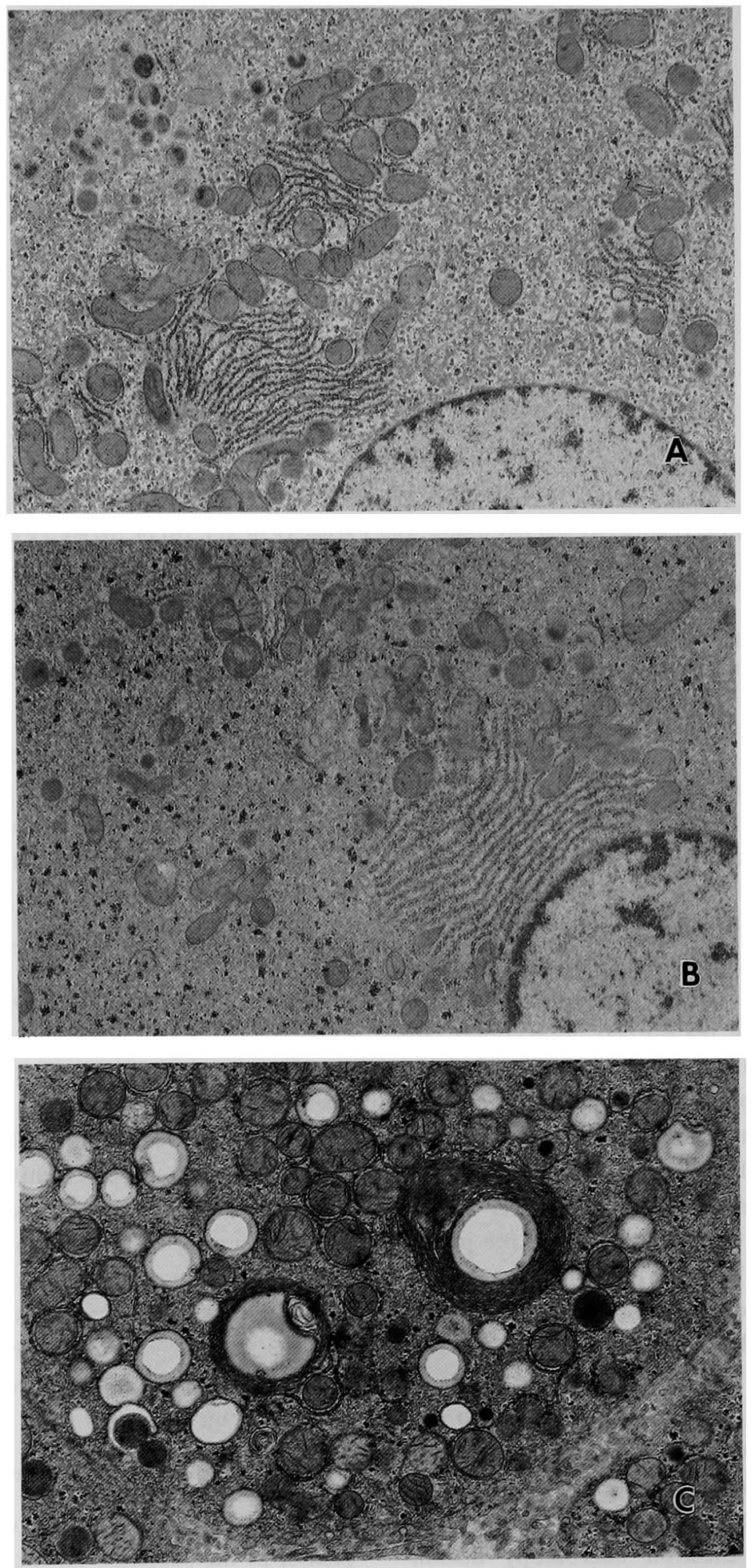
Table 4. Liver Microsomal Enzyme Levels ${ }^{\mathrm{B}}$

\begin{tabular}{lccl}
\hline Group & $\begin{array}{c}\text { Number of } \\
\text { animals }\end{array}$ & \multicolumn{1}{c}{ P-450 } & \multicolumn{1}{c}{ UDP-GT $^{\mathrm{b}}$} \\
\hline Control & 5 & $0.534 \pm 0.120$ & $11.3 \pm 1.45$ \\
SPL & 6 & $0.563 \pm 0.049$ & $11.2 \pm 2.38$ \\
PB & 3 & $1.069 \pm 0.134^{* * *}$ & $32.9 \pm 2.04^{* * *}$ \\
\hline
\end{tabular}

all rats were treated for 13 weeks with SPL or PB.

- Cytochrome P-450 contents are expressed as $\mathrm{mol} / \mathrm{mg}$ protein.

c One unit of activity is equal to $1 \mathrm{nmol} p$-nitrophenal glucuronide formed per $\mathrm{mg}$ protein per minute.

Data represent the mean $\pm S D$.

***, $\mathrm{p}<0.001$ for comparison with control values (Student's $t$-test).

SPL, spironolactone; PB, phenobarbital

significant increase in cytochrome $\mathbf{P}-\mathbf{4 5 0}$ content could be detected in the same group at week 13 . On the other hand, male rats treated with SPL had neither changes in UDP-GT activity nor in P-450 content.

\section{Discussion}

Thirteen weeks of treatment with $150 \mathrm{mg} / \mathrm{kg}$ of SPL and $100 \mathrm{mg} / \mathrm{kg}$ of PB induced increased thyroid weights and follicular cell hypertrophy in male rats. The patterns of elevated serum TSH and transiently decreased serum $T_{4}$ and $T_{3}$ suggest that TSH stimulation occurs secondary to declined $T_{4}$ and $T_{3}$ levels, giving rise to morphologic changes in the thyroid gland ${ }^{24}$. Serum thyroid hormone level are regulated by a feed back mechanism in the pituitary gland; decreased levels of thyroid hormone resulted in increased TSH release from the pituitary. In thyroids of animals treated with PB or SPL, ultrastructually the follicular epithelial cells possessed abundant apical vesicles beneath the apical plasma membrane. These changes appear not to imply degenerative process, but to represent colloid biosynthesis ${ }^{25}$. Decreases in $T_{4}$ and $T_{3}$ observed in animals treated with PB or SPL were probably not due to lowered iodide uptake and organification by thyroid. Because, McClain et al. and Semler et al.reported that each drug treatment results in increased iodide uptake and organification by thyroid ${ }^{20,26}$. Their data also indicate that PB or SPL do not directly affect thyroid hormone synthesis.

In animals treated with PB or SPL, enlarged hepatocytes accompanied by smooth endoplasmic reticulum proliferation were observed, and hepatic microsomal enzyme activity was enhanced. The induction of hepatic microsomal enzymes enhances the metabolism of the thyroid hormone ${ }^{4,5,11}$. Comer et al. demonstrated that thyroid change induced by potassium prorenoate (analogue of SPL) administration, follicular epithelial hypertrophy took place secondary to increased hepatic microsomal enzyme activity ${ }^{27}$.

Thyroid hormone can be metabolized via glucuronidation (UDP-GT), oxidation (P-450), and deiodination (monodeiodinase) etc. ${ }^{10}$. In rodent, it is well known that UDP-GT is the most common pathway of $\mathrm{T}_{4}$ clearance $^{28}$. By studies with benzpyrene, the induction of UDP-GT activity toward $p$-nitrophenol has been shown to be a good marker for induction of UDP-GT activity toward $T_{4}{ }^{8,29}$. In this study, treatment with $P B$ increased both UDP-GT activity toward $p$-nitrophenol and induction of $\mathrm{P}-450$. These data indicate that the induction of hepatic microsomal enzymes (UDP-GT and P-450) by PB treatment becomes an important factor for metabolism of the thyroid hormone. On the other hand, although SPL-treated animals showed hepatic smooth endoplasmic reticulum proliferation, induction of UDP-GT and P-450 in their livers was not observed. Two hundred $\mathrm{mg} / \mathrm{kg}$ of SPL administered for two weeks has been shown to increase the glucuronidation of $p$-nitrophenol in rats ${ }^{20}$. In our another study, however, SPL administration at the same dose for two weeks increased thyroid weight but not glucuronidation. Increased thy-

Fig. 4. Electron micrographs of livers from rats treated with $150 \mathrm{mg} / \mathrm{kg}$ of SPL (A) and $100 \mathrm{mg} / \mathrm{kg}$ of PB (B, C) for 13 weeks.

A. A rat treated with SPL. $\times 10,500$. Smooth endoplasmic reticulum proliferation can be seen in a centrilobular hepatocyte.

B. and C. A rat treated with PB. $\times 10,500$. The membranes of the endoplasmic reticulum formed a whorl in the cytoplasm, enclosing lipid droplets (concentric membranous body) that are present in a centrilobular hepatocyte. 

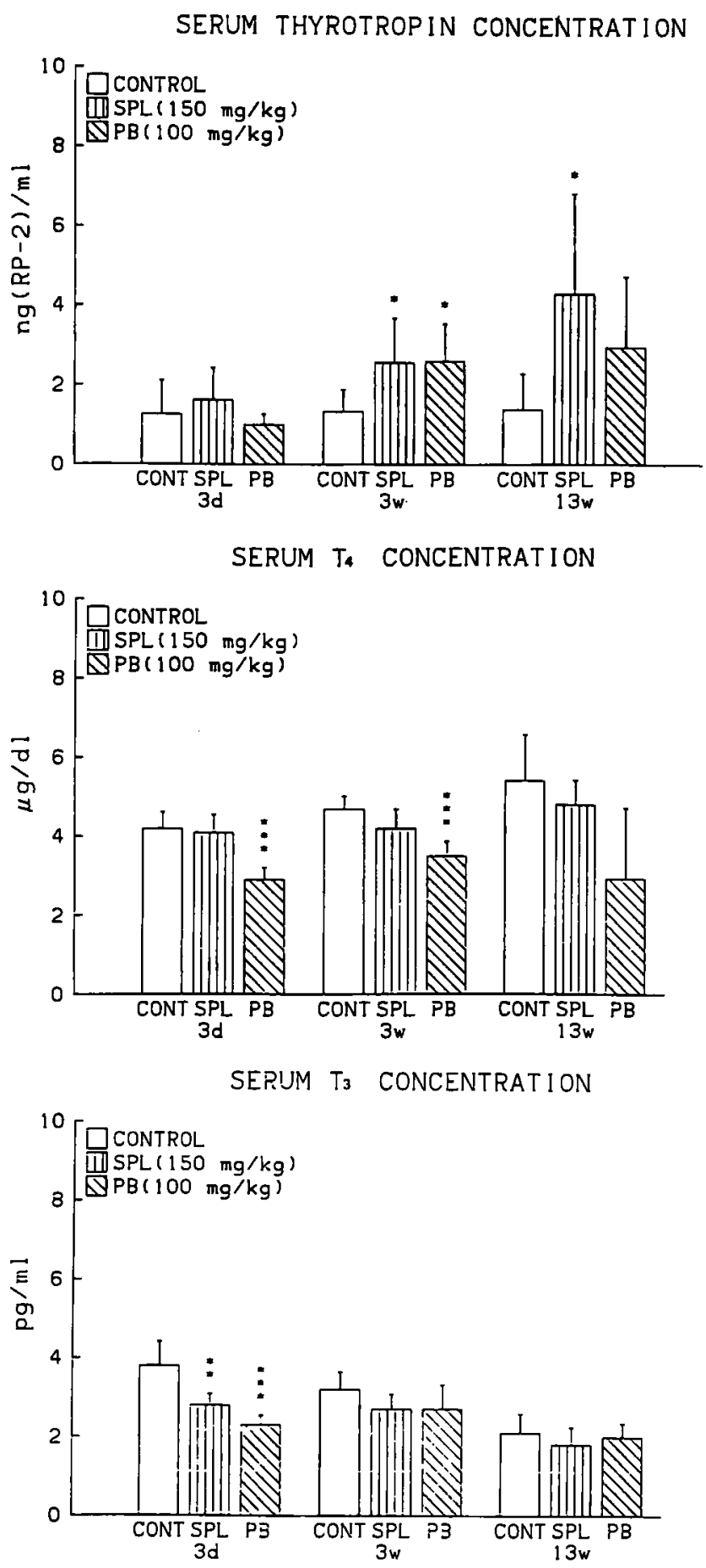

Fig. 5. Serum TSH (ng (RP-2)/ml) (A), $T_{4}(\mu \mathrm{g} / \mathrm{dl})(B)$, and $T_{3}(\mathrm{pg} / \mathrm{ml})(C)$ concentrations after 3 days, 3 weeks, and 13 weeks of treatment with spironolactone at $0,150 \mathrm{mg} / \mathrm{kg}$ and phenobarbital at $100 \mathrm{mg} / \mathrm{kg}$. Values are means $\pm S D$ of three to six rats per group. The asterisk indicates values significantly different from the control at $p<0.05$ (Student's $t$-test). 
roid weight in rats fed at $6 \mathrm{mg} / \mathrm{kg}$ of SPL, while no effect on $T_{4}$ level could be detected ${ }^{24}$. Ten $\mathrm{mg} / \mathrm{kg}$ administration of SPL failed to increase UDP-GT activity toward $p$-nitrophenol in rats ${ }^{30}$. Thus, it appears unlikely that decreases in serum $T_{4}$ and $T_{3}$ seen in the SPL-treated group, resulted from hepatic clearance by UDP-GT and P-450.

Inducers of the enzymes involved in foreigncompound metabolism have been devided into the least two different categories on the basis of their characteristic effects on cytochrome P-450 and monooxygenase activity ${ }^{31-33}$. One of these, PB, led to a significant increase in liver size and weight and caused the substantial proliferation of hepatic endoplasmic reticulum. This induction was associated with increases in cytochrome $\mathrm{P}-450$, in rats, is referred to as cytochrome $\mathrm{P}-450 \mathrm{~b}^{33}$. The other one, 3-methyl cholanthrene (3MC) did not cause large increases in liver size or in the proliferation of endoplasmic reticulum; nether did it result in large increases in cytochrome $\mathrm{P}-450$. $3 \mathrm{MC}$ resulted in the induction of qualitatively differed from cytochrome $\mathbf{P}-450$, in rats, is referred to as cytochrome $\mathbf{P}-450 \mathrm{c}^{31,33}$. In this study, SPL led to a significant increase in liver weight and substantial proliferation of hepatic endoplasmic reticulum, but did not it result in large increases in cytochrome P-450. Therefore, our study suggests the possibility that increased levels of a distinct spectrum of isozymes of cytochrome P-450 and other enzymes may cause decreases in $T_{4}$ and $T_{3}$ in SPL-treated rats. Many of the same comments apply to the UDP-GT assay.

In conclusion, the thyroidal effect of $\mathrm{PB}$ in rats is mainly due to TSH stimulation, a compensatory response to decreased thyroid hormone level by induction of the hepatic microsomal enzymes (UDP-GP and P-450). In contrast, in SPL-treated rats, a distinct spectrum of isozymes of $P-450$ and UDP-GT and other enzymes may play an important role for thyroid hormone homeostasis.

\section{References}

1. Werk, EE, Jr, Thrasher, K, Sholiton, LJ, Olinger, C, and Choi, Y: Cortisol production in epileptic patients treated with diphenylhydantion. Clin Pharmacol Ther 12: 698-703, 1971.
2. Levin, W, Welch, RM, and Conney, AH : Increased liver microsomal androgen metabolism by phenobarbital : correlation with decreased androgen action on the seminal vesicles of the rat. J Pharmacol Exp Ther 188 : 287-292, 1974.

3. Bolt, HM, Bolt, $\mathbf{M}$, and Kappus, $\mathbf{H}$ : Interaction of rifampicin treatment with pharmacokinetics and metabolism of ethinyloestradiol in man. Acta Endocrinol 85: 189-197, 1977.

4. Myant, NB : The biliary excretion of thyroid hormone. Lect Sci Basis Med 6 : 313-332, 1958.

5. Taurog, A : Conjugation and excretion of thyroid hormone. Brookhaven Symp Biol 7: 111-136, 1955.

6. Conney, AH : Pharmacological implications of microsomal enzyme induction. Pharmacol Rev 19 : 317-366, 1967.

7. Japundzic, MM : The goitrogenic effect of phenobarbital-Na on the rat thyroid. Acta Anat 74: 88-96, 1969.

8. Goldstein, JA and Taurog, A : Enhanced biliary excretion of thyroxine glucuronide in rats pretreated with benzpyrene. Biochem Pharmacol 17: 10491065,1968

9. Bernstein, G, Artz, SA, Hasen, J, and Oppenheimer, JH : Hepatic accumulation of ${ }^{125}$ I-thyronine in the rat : augmentation by phenobarbital and chlordane. Endocrinology 82 : 406-409, 1968.

10. Cavalier, RR and Pitt-Rives, $R$ : The effects of drugs on the distribution and metabolism of thyroid hormones. Pharmacol Rev 33: 55-80, 1981.

11. McClain, RM: The significance of hepatic microsomal enzyme induction and altered thyroid function in rats: Implications for thyroid gland neoplasia. Toxicol Pathol 17: 294-306, 1989.

12. Brown, JJ, Davies, DL, Ferriss, JB, Fraser, R, Haywood, E, and Lever, AF : Comparison of surgery and prolonged spironolactone therapy in patients with hypertension, aldosterone excess, and low plasma renin. Br Med J 2: 729-734, 1972.

13. Mantero, F, Armanini, D, and Urban, S : Antihypertensive effect of spironolactone in essential, renal and mineralocorticoid hypertension. Clin Sci Mol Med 45 (Suppl. 1) : 219S-224S, 1973.

14. Carey, RM, Douglas, JG, Schweikert, JR, and Liddle, GW: The syndrome of essential hypertension and suppressed plasma renic activity : normalization of blood pressue with spironolactone. Arch Intern Med 130 : 849-854, 1972.

15. Crane, MG, Harris, JJ, and Johns, VJ, Jr : Hyporeninemic hypertension. Am J Med 52 : 457-466, 1972.

16. Spark, RF, O'Hare, CE, and Regan, RM : Lowrenin hypertension: restoration of normotension and renin responsiveness. Arch Intern Med 133: 205-211, 1974.

17. Liddle, GW : Aldosterone antagonists and triamterene. Ann NY Acad Sci 139 : 466-470, 1966.

18. Ross, EJ : Aldosterone and its antagonists. Clin Pharmacol Ther 6: 65-106, 1965.

19. Lumb, G, Newberne, P, Rust, JH, and Wagner, B : 
Effects in animals of chronic administration of spironolactone-A review. J Environ Pathol Toxicol 1 : 641-660, 1978.

20. Semler, DE, Chengelis, CP, and Radzialowski, FM : The effects of chronic ingestion of spironolactone on serum thyrotropin and thyroid hormones in the male rat. Toxicol Appl Pharamacol 98 : 263-268, 1989.

21. Rossi, L, Ravera, M, Repetti, G, and Santi, L: Long-term administration of DDT or Phenobarbital-Na in Wistar rats. Int J Cancer $19:$ 179-185, 1977.

22. Omura, $\mathbf{T}$ and Sato, $\mathbf{R}$ : The carbon monoxide-binding pigment of liver microsomes. II. Solubilization, purification, and properties. J Biol Chem 239 : 2379-2385, 1964.

23. Bock, K, Frohling, W, Remner, H, and Rexer, B : Effects of phenobarbital and 3-methylcholanthrene on substrate specificity of rat liver microsomal UDP-glucuronosyl transferase. Biochim Biophys Acta 327 : 46-56, 1973.

24. Hum, AW and Cormach, DH : In : Histology, 8th ed., Lppincott, Philadelphia/Toronto, pp. 801-807, 1979.

25. Wetzet, BK, Spicer, SS, and Wollman, SH : Changes in fine structure and acid phosphatase localization in rat thyroid cells followong thyrotropin administration. J Cell Biol 25: 593-618, 1965.

26. McClain, RM, Levin AA, Posch, R, and Downing, JC : The effect of phenobarbital on the metabolism and excretion of thyroxine in rats. Toxicol Appl
Pharmacol 99 : 216-228, 1989.

27. Comer, CP, Chengelis, CP, Levin, S, and Kotsonis, FN : Changes in thyroidal function and liver UDP glucuronosyl transferase activity in rats following administration of a Novel Imidazole (SC-37211). Toxicol Appl Pharmacol 80 : 427-436, 1985.

28. Akoso, B, Sleight, S, Nachreiner, R, and Aust, $\mathbf{S}$ : Effects of purified polybrominated and biphenyl congeners on the thyroid and pituitary glands in rats. J Am Coll Toxicol 1 : 23-26, 1982.

29. Watkins, JB, Gregus, Z, Thompson, TN, and Klaassen, $C D$ : Induction studies on the functional heterogeneity of rat liver UDP-glucuronosyl transferases. Toxicol Appl Pharmacol 64 : 439-446, 1982.

30. Ricci, GL, Baldassarre, V, Zanninelli, G, and Cuppone, $R$ : Comparison of the effect of spironolactone and $\mathrm{K}^{+}$-canrenoate on cytochrome $\mathrm{P}$ 450 and in vitro glucuronidation of rat liver. Ital $\mathrm{J}$ Gastroenterol 18 : 73-76, 1986.

31. Lu, AYH, and West, SB : Reconstituted mammalian mixed-function oxidases: Requirements, specifications, and other properties. Pharmacol Ther A 2 : 337-358, 1978.

32. Lu, AYH and West, SB : Multiplicity of mammalian microsomal cytochromes P-450. Pharmacol Rev 31 : 277-295, 1980.

33. Ryan, D, Lu, AYH, and Levin, W : Purification of cytochrome $\mathrm{P}-450$ and $\mathrm{P}-448$ from rat liver microsomes. Methods Enzymol 52 : 117-123, 1978. 